\title{
QUALITY OF LIFE IN PATIENTS SUBMITTED TO SURGICAL TREATMENT OF IDIOPATHIC SCOLIOSIS
}

\author{
João Bernardo Sancio Rocha Rodrigues ${ }^{1}$, Nathália Ambrozim Santos Saleme ${ }^{1}$, José lucas Batista Junior ${ }^{2}$, \\ IgOR MACHAdo CARDOSO$^{2}$, Charbel Jacob Junior ${ }^{2}$
}

\section{ABSTRACT}

Objective: To evaluate quality of life, using the SF-36, in patients with adolescent idiopathic scoliosis (AIS) who underwent surgery for deformity correction, comparing the results in the pre-and post-operative period. Methods: We evaluated 29 patients, 24 female, mean age 14.5 years, all patients had measurement of Cobb angle greater than $50^{\circ}$, and responded to the SF-36 questionnaire preoperatively and on average two years after surgery. Results: There was improvement in all eight domains studied by the
SF-36 after surgical treatment, with statistically significant improvement of the domains functional capacity physical aspects, pain and general state. Vitality and mental health were those with the lowest percentage of improvement postoperatively. Conclusion: Surgical treatment of deformity in all AIS improved the functional aspects assessed by the SF-36, representing, in practice, better quality of life for these patients. Evidence Level II, Prospective Study.

Descriptors: Scoliosis/surgery.Treatment outcome. Quality of life.

Citation: Rodrigues JBS, Saleme NAS, Batista Junior JL, Cardoso IM, Jacob Junior C. Quality of life in patients submitted to surgical treatment of idiopathic scoliosis. Acta Ortop Bras. [online]. 2015;23(6):287-9. Available from URL: http://www.scielo.br/aob.

\section{INTRODUCTION}

Idiopathic scoliosis is the lateral deviation in the frontal plane of the spine larger than 10 degrees, for which there is no established cause, which affects approximately $2-3 \%$ of the general population, with a higher prevalence in female adolescents. The most common complaint is aesthetical, however, pain, paresthesia, and changes or loss of sphincter balance may also occur., ${ }^{1,2}$

Although the etiology of idiopathic scoliosis remains unknown, there are several multifactorial theories as neuromuscular or connective tissue disorders, hereditary factors, changes in sagittal configuration of the spine, asymmetric growth of the limbs and trunk, besides environmental factors, such as nourishment. ${ }^{3-6}$ Studies have shown that untreated scoliosis result in a higher incidence of pain and increasing disability, which can lead to issues at work and marital relations, besides causing respiratory distress and early death. ${ }^{7-9}$ For more serious cases, it is the orthopedist decision to indicate surgery, aiming to prevent the progression of the disease, correct the curve and maintain the spine balance..$^{10}$ However, even with appropriate treatment established, it is known that in severe deformities there is a significant negative impact on the patient's quality of life, affecting daily activities common to their age and psychosocial development of adolescents. ${ }^{11}$
The term quality of life has been used in health disciplines since 1970. It is a multidimensional construct that captures the impact of health status, including disease and treatment in the physical, psychological and social function domains. Usually, the quality of life in health is evaluated through questionnaires because they show greater reliability in treatment evaluation, allowing revealing positive or even negative interference in patients' lives. When analyzing the quality of life of patients with adolescent idiopathic scoliosis (AIS) in the pre- and postoperative periods through the SF-36 questionnaire, we believe providing important data on how this disease interferes with the lives of these patients and, with this understanding, to facilitate care and the doctor-patient relationship, increasing patients' adherence to treatment. ${ }^{12,13}$

\section{MATERIALS AND METHODS}

This is a prospective study that evaluated 29 patients with a mean age of 14.53 years old, 24 females, who underwent surgery at the Spine Surgery Group of Hospital Santa Casa de Misericordia de Vitoria (HSCMV), Vitória, ES, Brazil. This research project was approved by the institutional Ethics Committee for Research with human subjects of Escola Superior de Ciências da Santa Casa de Misericórdia de Vitória (EMESCAM) under number 018/2012. All patients signed the Free and Informed Consent Form (FICF).

All the authors declare that there is no potential conflict of interest referring to this article.

\footnotetext{
1. Santa Casa de Misericórdia de Vitória, Escola Superior de Ciências, (EMESCAM), Vitória, ES, Brazil 2. Hospital Santa Casa de Misericórdia de Vitória (HSCMV), Spine Group, Vitória, ES, Brazil.

Work developed at Hospital Santa Casa de Misericórdia de Vitória (HSCMV), Department of Surgical Clinics, Orthopedics and Traumatology Sector, Vitória, ES, Brazil. Correspondence: Charbel Jacob Junior, Rua Dr. João dos Santos Neves, 143, Vila Rubim 29018-180 Vitória, ES, Brasil. grupodecoluna@santacasavitoria.org
} 
We used as inclusion criteria all patients with AIS treated at HSCMV with curves over $50^{\circ}$, who responded to SF-36 questionnaire pre- and postoperatively. Exclusion criteria were other causes of scoliosis, patients with curves that received conservative treatment indication, or those who did not have preoperative quality of life evaluation protocols.

Patients were submitted to SF-36 questionnaire preoperatively and on average 24 months after surgery. The SF-36 questionnaire to assess quality of life can be self-administered by computer, telephone or by a trained interviewer, which contains 36 items that measure mental and physical health components through eight domains: functional capacity, limitations due to physical aspects, pain, general health status, vitality, social aspects, emotional aspects and mental health.

Regarding statistical analysis we initially applied the Kolmogorov-Smirnov test, used to assess whether data followed a normal distribution, as shown in Table 1.

The variables functional capacity, general health status, vitality and mental health showed to be normally distributed and correlated using the Student $t$-test for paired data. For non-normal variables, we used the Wilcoxon test, which is a non-parametric technique equivalent to the Student $t$-test for paired data. ${ }^{14}$

Values of $p \leq 0.05$ were considered statistically significant. The statistical analysis was performed using Microsoft Office Excel 2010 software and SPSS (Statistical Package for Social Sciences) version 8.0.

Table 1. Result of statistical significance (p) of each domain of SF36 according to Kolmogorov Smirnov test for verification of the data distribution pattern

\begin{tabular}{|c|c|c|c|c|c|c|c|c|}
\hline $\begin{array}{c}\text { Domains of } \\
\text { SF-36 }\end{array}$ & FC & PA & $\mathbf{P}$ & GHS & V & SA & EA & MH \\
\hline Significance* & 0.125 & 0.000 & 0.034 & 0.450 & 0.730 & 0.018 & 0.000 & 0.178 \\
\hline
\end{tabular}

\section{RESULTS}

The results showed improvement in all eight domains evaluated by the SF-36 questionnaire comparing pre- and post-operative patients undergoing surgery for spinal scoliosis correction. (Figure 1) In Figure 1 we observe a marked improvement in SF-36 average score after surgery for physical aspects functional domain, with an average increase over 20 points. In contrast, the variable vitality had the lowest percentage of improvement postoperatively compared to the average before surgery.

By correlating the data obtained from the statistical analysis, we find that among the evaluated domains, functional capacity, physical aspects, pain and general health status showed statistically significant improvement between periods. (Table 2) Among the eight domains evaluated, functional capacity, physical aspects and pain showed greater level of significance when compared, reflecting an improvement in the practice of daily activities, including vigorous ones, with reduced or no pain or limitations secondary to pain.

Although there is no statistical significance for the domain related to social aspects $(p=0.055)$, the level of significance found very was close to 0.05 . Regarding the pain domain, we noticed that 21 patients, equivalent to $72.42 \%$ of the sample had some degree of improvement postoperatively, whereas in the vitality domain, only 11 patients noticed improvement after surgery (37.93\%).

\section{DISCUSSION}

In this article we used the SF-36 questionnaire to evaluate the quality of life of patients with AIS due to convenience. This questionnaire can be applied to more than 130 conditions, including spinal-related problems, which may considerably affect the quality of life related to health. ${ }^{15-18}$

When analyzing the general result of surgical treatment of AIS by applying the SF-36 questionnaire, we observed a significant improvement in quality even after two years of surgical correction. We believe that this period after surgery can provide an idea on how the surgery can interfere with the quality of life of these patients. Pellegrino and Avanzi, ${ }^{19}$ in a similar study conducted recently, observed a worsening of pain and functional capacity of patients in the early postoperative period (up to

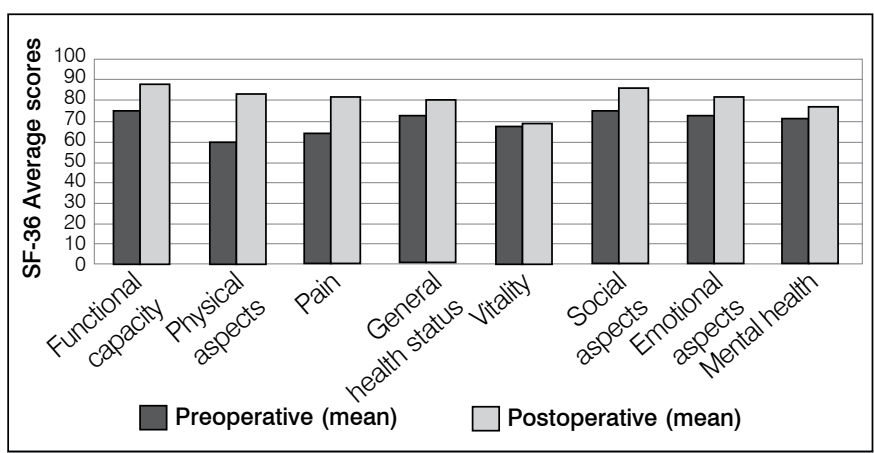

Figure 1. Comparison between mean values of SF-36 domains on pre and postoperative periods.

Table 2. Comparison between the overall averages for each functional domain of SF-36 in the pre- and postoperative period, regarding their respective percentage of improvement after surgery.

\begin{tabular}{|c|c|c|c|c|}
\hline Domains of SF-36 & $\operatorname{Pre}\left(\right.$ mean) ${ }^{* \star}$ & Post (mean) ${ }^{* \star}$ & Improvement & Significance $(p)$ \\
\hline Functional capacity & 75.00 & 87.24 & $16.32 \%$ & $0.006^{\star}$ \\
\hline Physical aspects & 59.65 & 82.75 & $38.72 \%$ & $0.01^{*}$ \\
\hline Pain & 64.37 & 81.68 & $26.89 \%$ & $0.001^{*}$ \\
\hline General health status & 72.27 & 80.17 & $10.93 \%$ & $0.026^{*}$ \\
\hline Vitality & 67.93 & 68.79 & $1.26 \%$ & 0.819 \\
\hline Social aspects & 75.00 & 85.43 & $13.90 \%$ & 0.055 \\
\hline Emotional aspects & 72.37 & 81.46 & $14.30 \%$ & 0.268 \\
\hline Mental health & 71.03 & 76.44 & $7.61 \%$ & 0.278 \\
\hline
\end{tabular}

Pre: preoperative period; Post: postoperative period. ${ }^{*} \mathrm{p} \leq 0.05^{* *}$ Values may vary on a scale from $1-100$, where 100 is the best possible score.

three months), with significant improvement when they were re-evaluated after 12 months of treatment.

An important outcome of this study was a statistically significant improvement in functional capacity, pain and physical aspect, a result similar to that found by Cabral et al. ${ }^{17}$ The literature reports that the incidence of pain in scoliosis is comparable to the incidence in the general population. ${ }^{1}$ In our study, we found improvement in spinal pain in $72.42 \%$ of the sample, which leads us to believe that we need to consider its prevalence in these patients. The improvement in physical appearance makes it clear that scoliosis is a physical problem that slightly interferes on vitality and mental health. We, as well, found some impro- 
vement in such domains, although not statistically significant. The topic quality of life has become so important in the analysis of postoperative results of IAS that less aggressive surgical techniques for treatment have been advocated, such as selective arthrodesis, where the goal is to perform arthrodesis in as minimum levels as possible, since the spine stiffness in the segment is a constant concern regarding the quality of life of these patients. Despite all the discussion on the topic, we did not yet found in the literature any work that directly shows improvement of quality of life with fewer arthrodesis. What currently exists, and was found in our study, is that surgical treatment of spinal scoliosis, when necessary, improves the quality of life of patients regardless the number of levels on which in which arthrodesis was performed. ${ }^{20}$

\section{CONCLUSION}

Surgical treatment of IAS improved all functional aspects assessed by SF-36 questionnaire, representing, in practice, improvement in the quality of life of these patients.

\section{ACKNOWLEDGEMENTS}

The authors are deeply indebted to Dr. Rodrigo Rezende (in memoriam), our beloved teacher and mentor. The authors also acknowledge the Espírito Santo Research Foundation (FAPES) for financial support to fellow participant of Programa Institucional de Bolsas de Iniciação Científica (PIBIC) of EMESCAM.

\section{REFERENCES}

1. Weinstein SL. Adolescent Idiopathic Scoliosis: Natural History. In: Weinstein SL. Pediatric spine: the principles and practice. 2nd ed. lowa: Lippincott Williams \& Wilkins; 2001. p.356-67.

2. Bunnell WP. The natural history of idiopathic scoliosis. Clin Orthop Relat Res. 1988;(229):20-5.

3. Beals RK. Nosologic and genetic aspect of scoliosis. Clin Orthop Relat Res. 1973;(93):23-32.

4. Cowell HR, Hall JN, MacEwen GD. Genetic aspects of idiopathic scoliosis. Clin Orthop Relat Res. 1972;86:121-31.

5. Kouwenhoven JW, Castelein RM. The pathogenesis of adolescent idiopathic scoliosis: review of the literature. Spine (Phila Pa 1976). 2008;33(26):2898-908

6. Ahn UM, Ahn NU, Nallamshetty L, Buchowski JM, Rose PS, Miller NH, et al. The etiology of adolescent idiopathic scoliosis. Am J Orthop (Belle Mead NJ). 2002;31(7):387-95.

7. Fowles JV, Drummond DS, L'Ecuyer S, Roy L, Kassab MT. Untreated scoliosis in the adult. Clin Orthop Relat Res. 1978;(134):212-7.

8. Pehrsson K, Larsson S, Oden A, Nachemson A. Long-term follow-up of patients with untreated scoliosis. A study of mortality, causes of death, and symptoms. Spine (Phila Pa 1976). 1992;17(9):1091-6.

9. Weinstein SL, Ponseti IV. Curve progression in idiopathic scoliosis. J Bone Joint Surg Am. 1983;65(4):447-55.

10. Danielsson AJ, Wiklund I, Pehrsson K, Nachemson AL. Health-related quality of life in patients with adolescent idiopathic scoliosis: a matched follow-up at least 20 years after treatment with brace or surgery. Eur Spine J. 2001;10(4):278-88.

11. Goldberg MS, Mayo NE, Poitras B, Scott S, Hanley J. The Ste-Justine Adolescent

Acta Ortop Bras. 2015;23(5):287-9
Idiopathic Scoliosis Cohort Study. Part II: Perception of health, self and body image, and participation in physical activities. Spine (Phila Pa 1976). 1994;19(14):1562-72.

12. Seidl EM, Zannon CM. Quality of life and health: conceptual and methodological issues. Cad Saude Publica. 2004;20(2):580-8.

13. Patel AA, Donegan D, Albert T. The 36-item short form. J Am Acad Orthop Surg. 2007;15(2):126-34.

14. Siegel S, Castellan Junior NJ. Estatística não-paramétrica para ciências do comportamento. 2a. ed. Porto Alegre: Artmed; 2006.

15. Ware JE Jr. SF-36 health survey update. Spine (Phila Pa 1976). 2000;25(24):3130-9.

16. Falavigna A, Teles AR, Braga GL, Barazzetti, DO, Lazzaretti L, Tregnago AC. Instrumentos de avaliação clínica e funcional em cirurgia da coluna vertebral. Coluna/Columna. 2011;10(1):62-7.

17. Cabral LTB, Valesin Filho ES, Ueno FH, Yonezaki AM, Rodrigues LMR. Avaliação da qualidade de vida em pacientes com escoliose idiopática do adolescente após tratamento cirúrgico pelo questionário SF-36. Coluna/Columna. 2009;8(3):315-22

18. Patrick DL, Deyo RA, Atlas SJ, Singer DE, Chapin A, Keller RB. Assessing health-related quality of life in patients with sciatica. Spine (Phila Pa 1976). 1995;20(17):1899-908.

19. Pellegrino LN, Avanzi O. Prospective evaluation of quality of life in adolescent idiopathic scoliosis before and after surgery. J Spinal Disord Tech. 2014;27(8):409-14

20. Negrini S, Grivas TB, Kotwicki T, Maruyama T, Rigo M, Weiss HR. Why do we treat adolescent idiopathic scoliosis? What we want to obtain and to avoid for our patients. SOSORT 2005 Consensus paper. Scoliosis. 2006;1:4. 